\title{
Interstitial radiotherapy using phosphorus-32 for giant posterior fossa cystic craniopharyngiomas
}

\author{
Xin Yu, MD, PhD, ${ }^{1}$ Jianning Zhang, MD, PhD, ${ }^{1}$ Rui Liu, MD, ${ }^{1}$ Yaming Wang, MD, ${ }^{1}$ \\ Hongwei Wang, MD, ${ }^{1}$ Peng Wang, MD, ${ }^{1}$ Jinhui Chen, MD, ${ }^{1}$ and Song Liu, MD, PhD ${ }^{2,3}$
}

\begin{abstract}
1Department of Neurosurgery, Navy General Hospital, Beijing; ${ }^{2}$ Beijing Neurosurgical Institute and Department of Neurosurgery, Beijing Tiantan Hospital, Capital Medical University, Beijing, China; and 'UMR 788, INSERM et Université Paris-Sud, Le Kremlin-Bicêtre, France
\end{abstract}

\begin{abstract}
OBJECT The treatment for giant posterior fossa cystic craniopharyngiomas remains an important challenge in neurosurgery. The authors evaluated the effects of treating 20 patients with giant posterior fossa cystic craniopharyngiomas using phosphorus-32 (P-32) interstitial radiotherapy at their hospital.
\end{abstract}

METHODS The patients included 11 boys and 9 girls with an age range of 3 to 168 months. Before treatment, the tumor volumes ranged from 65 to $215 \mathrm{ml}$. The intracranial pressure was increased in 16 patients, and optic nerve damage had occurred in 18. The patients received P-32 interstitial radiotherapy following stereotactic cyst-fluid aspiration or drainage and were followed up for 7-138 months.

RESULTS The treatment immediately relieved the intracranial hypertension symptoms in all patients. At the end of follow-up, imaging examinations revealed that the cystic tumors had disappeared, but some residual calcification remained in 12 patients, and had decreased by more than $75 \%$ of the initial volume in 8 patients. The damaged optic nerve recovered in 3 cases, improved in 12 cases, remained unchanged in 1 case, and was aggravated in 2 cases. No other severe complications related to surgery or interstitial radiation occurred. During the follow-up period, 7 new cysts appeared in 5 patients who had received additional interstitial radiotherapies with a dose of P-32 that was calculated using the same formula as for the initial treatment. The new tumors then disappeared in 2 patients, significantly shrank in 2 patients, and progressed in 1 patient.

CONCLUSIONS For treating giant posterior fossa cystic craniopharyngiomas, P-32 interstitial radiation after stereotactic cyst-fluid aspiration or drainage can achieve a high tumor control rate and has relatively satisfactory clinical effects and quality of life outcomes with few complications.

http://thejns.org/doi/abs/10.3171/2014.10.PEDS14302

KEY WORDS giant cystic craniopharyngioma; interstitial radiotherapy; phosphorus-32; stereotactic radiosurgery; oncology

$\mathrm{C}$ RANIOPHARYNGIOMAS are slow-growing benign epithelial tumors that arise from remnants of Rathke's pouch. ${ }^{16}$ These tumors account for $2 \%-4 \%$ of all intracranial tumors and $10 \%$ of brain tumors that represent the most common nonglial tumors in children. ${ }^{10,25,35}$ Craniopharyngiomas are most commonly localized to the suprasellar region, although a subgroup of giant tumors may protrude upward into the third ventricle, downward into the sphenoid sinus and nasopharynx, forward into the frontal fossa, sideways into the temporal fossa, and back- ward into the posterior fossa. ${ }^{1,35}$ Although histologically benign, craniopharyngiomas may result in significant morbidity due to encroachment on or compression of the adjacent optic nerves and chiasm, pituitary gland, hypothalamus, and basal cerebrovasculature. Tumor-induced compression is particularly evident in giant craniopharyngiomas with a diameter greater than $4 \mathrm{~cm}$. Giant posterior fossa cystic craniopharyngiomas are rare and develop in children of both sexes equally. Clinically, giant posterior fossa cystic craniopharyngiomas increase the intracranial 
pressure and can damage the cranial nerves. However, the incidence and severity of pituitary and hypothalamus dysfunction is lower compared with common craniopharyngiomas.

Aggressive resection is considered the standard-of-care management for craniopharyngioma. Although progress in microsurgical techniques combined with advanced neuroimaging and intensive endocrinological replacement treatments has significantly reduced operative mortality, total resections of these tumors are often associated with neuropathies and/or eloquent brain injury. The tumor recurrence rates are as high as $66 \%$ if surgical treatment is performed alone, ${ }^{23,29,31,36}$ particularly for giant craniopharyngiomas. ${ }^{7,22,24,32}$ Therefore, an effective treatment is needed to achieve long-term tumor control, minimize treatment morbidity, preserve the hypothalamic-pituitary axis, and avoid postoperative visual and cognitive dysfunction.

Stereotactic intracavitary irradiation using pure betaemitting radioisotopes represents a minimally invasive treatment strategy for cystic craniopharyngiomas that is associated with a low risk of morbidity and mortality for patients. Moreover, targeted radiation for the cystic component delivered via an intracystic injection of a colloidal radioisotope proximal to the cyst wall was shown to successfully control the cystic components of these tumors. ${ }^{13,14,26,27,33}$ In this study, we retrospectively reviewed 20 cases of giant posterior fossa cystic craniopharyngiomas that were treated with interstitial radiotherapy using phosphorus-32 (P-32) after stereotactic cyst-fluid aspiration or drainage at our neurosurgical center, with the aim of obtaining useful information on effectively treating this tumor type.

\section{Methods \\ Study Population}

We identified and reviewed 20 patients with giant cystic craniopharyngiomas extending to the posterior fossa who were treated using intracystic irradiation with P-32 after stereotactic cyst-fluid aspiration or drainage between 2000 and 2011 at the neurosurgical center of the General Navy Hospital of China. This patient cohort included approximately $4.8 \%$ of the 418 patients with craniopharyngiomas admitted during the same time period. This retrospective review was performed with authorization from our hospital review board.

The criteria for giant posterior fossa cystic craniopharyngiomas included tumors originating from the sellar region and extending to the posterior fossa with a tumor diameter greater than $6 \mathrm{~cm}$ or a volume greater than 60 $\mathrm{ml}$. The sellar region is defined with an anterior border at the anterior clinoid process and the front edge of the sellar nodules, a posterior border at the posterior clinoid process and dorsum sellae, and side borders at the carotid artery sulcus. The main structure and adjacent organs of the sellar region include the sella turcica, diaphragma sellae, pituitary gland, cavernous sinus, suprasellar cistern, blood vessels on the sellar region, and the hypothalamus. The diagnosis was based on the patient's history, clinical presentation, typical imaging findings, extracted cyst-fluid examination (containing cholesterol crystal), and previous pathological diagnosis if the patient previously received surgical intervention. Primary tumors in the posterior fossa or the cerebellopontine angle were excluded.

The 20 evaluated patients consisted of 9 girls and 11 boys with a mean age of 7 years and a range of $0.25-14$ years. The disease history ranged from 0.5 to 12 months with a mean period of 5.5 months. Table 1 summarizes the information for the 20 patients regarding their clinical characteristics, presentations, and imaging findings. Based on previous literature and our own clinical data, almost all cases of giant posterior fossa cystic craniopharyngiomas develop in young children, and both sexes are affected equally. The most common clinical symptoms at presentation included headaches with nausea/vomiting and drowsiness due to intracranial hypertension $(n=16)$; optic nerve injury $(\mathrm{n}=18)$ including decreased vision, a visual field defect, and nerve atrophy; or other cranial nerve damage $(n=8)$ affecting the auditory nerve, facial nerve, abducens nerve, and oculomotor nerves. The less common symptoms included physical stunting $(\mathrm{n}=4)$, polydipsia and polyuria (including patients with diabetes; $\mathrm{n}=3$ ), and seizures $(n=2)$. There were 7 cases that showed hydrocephalus.

Brain CT and MRI showed typical imaging manifestations of giant posterior fossa cystic craniopharyngiomas in the 20 patients. All the tumors originated in the sellar region and extended to the posterior cranial fossa (unilateral 4 cases, bilateral 16 cases). Eight cases presented with tumors to the foramen magnum level, and 2 cases showed tumors that crossed the foramen magnum into the spinal canal (1 case up to the neck vertebral level). In 8 cases, the tumor moved into the anterior cranial fossa (unilateral 4 cases, bilateral 4 cases). There were 9 cases showing tumors in the middle cranial fossa (unilateral 3 cases, bilateral 6 cases) and 4 cases with tumors in the third ventricle. Fourteen cases presented as single cystic tumors, and 6 cases showed mixed cystic and solid tumors (single cyst in 1 case, double cysts in 2 cases, 3 cysts in 2 cases, 4 cysts in 1 case). The CT results showed that the cysts presented with low density in 8 cases, high density in 5 cases, isodensity in 2 cases, and mixed density in 5 cases (isodensity and high density in 4 cases, high density and low density in 1 case). Calcification was found in 19 cases, with typical wall eggshell calcification in 12 cases and irregular calcification in the solid part within the tumor in 7 cases. MRI results showed short T1 and long T2 signals in 9 cases, long T1 and T2 signals in 6 cases, isointense T1 and long T2 signals in 1 case, and mixed signals in 4 cases (short T1 and long T2, and long T1 and long T2). The tumor volumes ranged from 65 to $215 \mathrm{ml}$, with an average of $134.05 \mathrm{ml}$.

\section{Phosphorous-32 Radiotherapy}

For radioisotope P-32 interstitial radiotherapy, all patients received frame (Frame G, Leksell) or frameless (4 fiducials) stereotactic cyst-fluid aspiration (drainage) under local anesthesia, with the exception of patients under 5 years of age who received general anesthesia. Enhanced T1-weighted axial and coronal 3-mm-thick MR images were obtained, and the images were transferred to the 


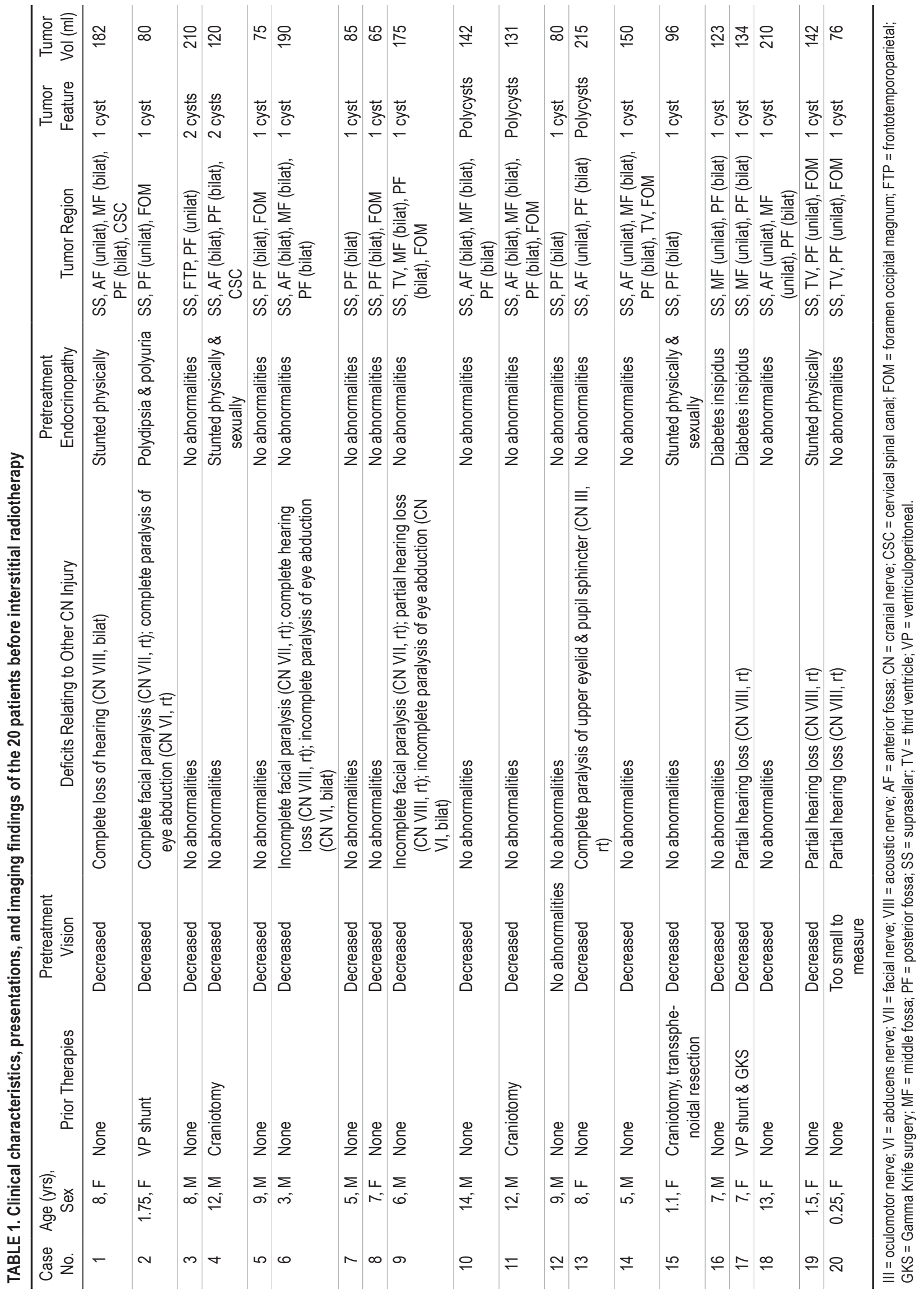


Aero Tech stereotactic surgery planning system (Image Processing Center, Beihang University, Beijing, China) to calculate the tumor volume and determine the target, surgery path, and puncture point. The tumor volume was automatically calculated by the system after labeling the tumor contour. This measurement was performed prior to cyst aspiration to calculate the appropriate dose of the P-32 radioisotope. In general, the puncture path should avoid sulci, ventricles, and any nerves and blood vessels. Based on the tumor location and anatomical relationship to the surrounding tissue, we determined the entrance points for these lesions. Among the 27 punctures in this study, 19 were performed via the supratentorial frontal pathway and 8 were performed through the infratentorial cerebellar hemisphere pathway. No reservoirs were left in any of the patients. If the tumor volume was less than $100 \mathrm{ml}$, direct cyst puncture was used to aspirate one-third to onehalf of the cyst fluid, and then the P-32 radioisotope was injected. If the tumor volume was greater than $100 \mathrm{ml}$, a fine silicone drainage tube with a $2-\mathrm{mm}$ outside diameter and a $1.5-\mathrm{mm}$ inside diameter was implanted for continuous or intermittent cyst fluid drainage. After 3-5 days, the P-32 isotope was injected through the drainage tube, and the tube was subsequently removed. The colloidal activity of the injected P-32 radioisotope was calculated based on even distribution within the tumor and a 150 Gy prescription dose for the cyst wall. The actual administration activity was determined using nomogram tables as follows: Activity $=0.1365 \times($ dose in Gy $) \times \operatorname{vol}(\mathrm{ml}) / 0.455$. These tables are based on a numerical calculation of dose delivered to a surface on the inner wall of a hollow sphere filled with a homogeneous mixture of radiocolloid and water. In all cases, the activity obtained from the nomogram was within 5\% of the calculated activity using the previous formula. Because the injected P-32 volume $(0.5-1.5 \mathrm{ml})$ was much smaller than the cystic volume $(>60 \mathrm{ml})$, there was little chance of leakage through the insertion hole.

\section{Results}

Table 2 summarizes the giant posterior fossa cystic craniopharyngiomas features before treatment, radioisotope P-32 interstitial radiotherapy, and treatment outcomes for the 20 patients. The patients received either frame or frameless stereotactic surgeries for cyst-fluid aspiration or drainage followed by $\mathrm{P}-32$ radioisotope interstitial radiotherapy. Depending on the cystic volume, either direct cyst puncture or a fine drainage silicone tube was used to aspirate the cyst fluid prior to P-32 injection. One patient who had 4 cysts underwent 2 stereotactic surgeries over an interval of 3 months, in which 2 cysts were treated during each surgery.

After the interstitial radiotherapy, the patients were followed-up for 7-138 months with an average of 48.6 months. The patients were regularly assessed via clinical observation, pituitary endocrine analysis, and radiological examinations every 6 months during the postoperative follow-up period. Clinically, intracranial hypertension symptoms were relieved in all 20 patients immediately after treatment. Posttreatment imaging showed that the ventricle volume returned to a normal size in the 7 patients who showed hydrocephalus prior to treatment. Among the 18 patients with optic nerve injury, the function of the damaged optic nerve was recovered in 3 cases, improved in 12 cases, unchanged in 1 case, and aggravated in 2 cases. Injuries to the other cranial nerves occurred in 8 patients. There was total recovery observed in 6 cases, partial recovery in 1 case, and unchanged status in 1 case. The examinations for endocrine function, including laboratory tests for pituitary endocrine function and other symptoms, showed that physical development was normal or improved after tumor shrinkage in the 4 patients who presented with delayed physical development (stature) resulting from growth hormone abnormalities. In the 3 cases with polydipsia and polyuria, 2 patients improved, and 1 showed no significant change. The 2 patients with established epilepsy who still had occasional epilepsy attacks while taking anticonvulsants before the stereotactic surgery and P-32 treatment demonstrated no epilepsy symptoms while taking the same dose of antiepileptic drugs as before the postoperative follow-up period. The MRI results showed that the cystic tumors completely disappeared, leaving some residual calcification, in 12 patients (Fig. 1) and that the tumor volume decreased by $75 \%$ in 8 patients (Fig. 2) during the posttreatment period (range 6-24 months, average 13.6 months).

Isotope leakage into the subarachnoid space may be an important sequela of radioisotope treatment that injures tissues adjacent to the tumor, such as the optic nerve, hypothalamus, pituitary gland, and internal carotid artery. To detect P-32 leakage after intracystic injection, we evaluated 6 randomly selected patients using gamma scintillation camera examination on the 1st day after treatment. We did not observe postoperative leakage of P-32 in any patient. Moreover, no other complications related to interstitial radiotherapy, such as injury to the internal carotid artery or hypothalamus, were found in any of the 20 patients during the follow-up period.

Five patients developed new cysts with an average volume of $6.4 \mathrm{ml}$ (range 3-11 ml) during the follow-up period. There were 2 patients with 2 new cysts that were discovered at 39 months and 43 months after the initial treatment. The other 3 patients each had 1 new cyst that was discovered at 6,9 , and 15 months after the initial treatment. These new tumors received a second course of interstitial P-32 radiotherapy, and the dose was calculated using the same formula as for the initial treatment. During the supplementary follow-up period of 8-66 months, the tumors completely disappeared in the 2 patients with 2 new cysts (Fig. 3), significantly shrank in 2 patients with 1 new cyst, and progressed in 1 patient with 1 new cyst. The tumor control rate for these new tumors was $85.7 \%$.

\section{Discussion}

Giant craniopharyngiomas, such as giant posterior fossa cystic craniopharyngiomas, occur at a low incidence and differ from common craniopharyngiomas. Statistically, giant cystic craniopharyngiomas account for $4 \%-9 \%$ of all craniopharyngiomas, and giant posterior fossa cystic craniopharyngiomas represent only $4 \%$ of all craniopharyngiomas and are mainly composed of polycysts. ${ }^{6,25}$ The 


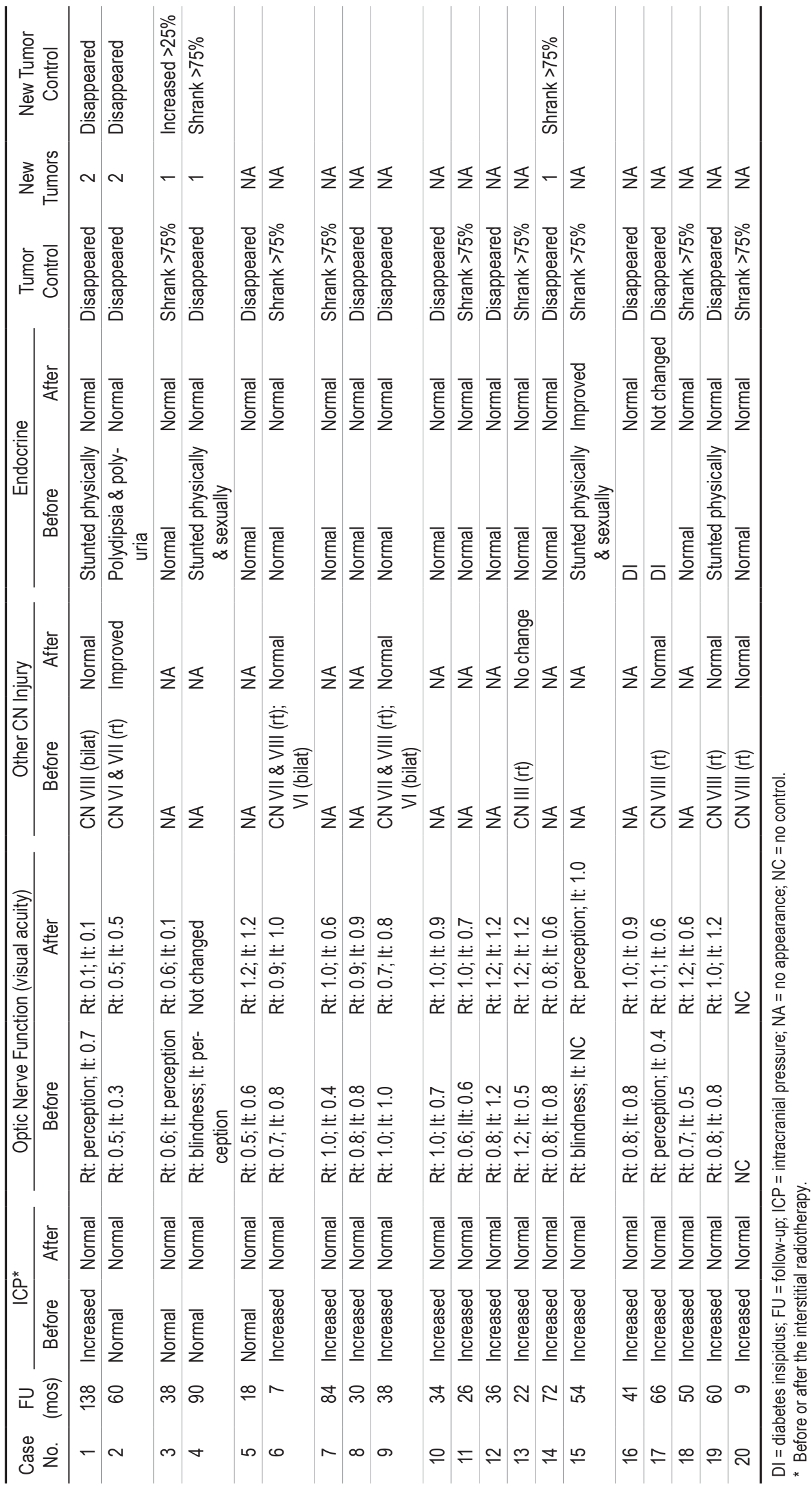



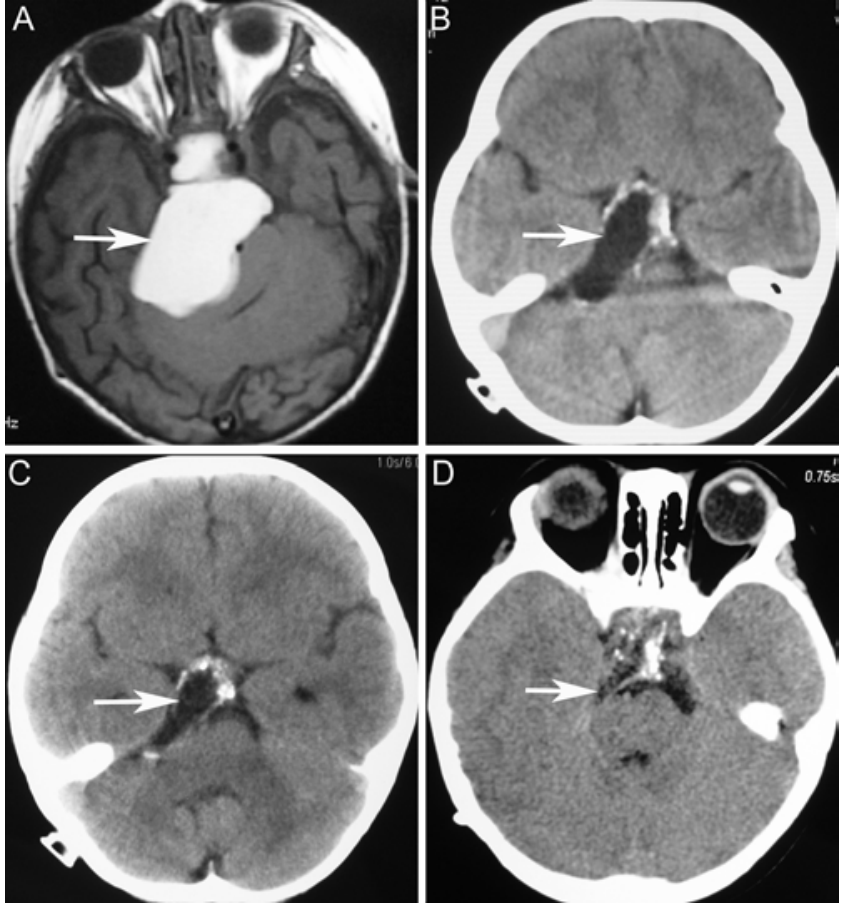

FIG. 1. Case 2. Axial T1-weighted MR images in a 20-month-old girl diagnosed with craniopharyngioma by MRI after suffering from a mouth askew on the left side for 3 months. The authors detected a giant craniopharyngioma (arrow) originating from the sellar region and extending to the posterior fossa (A). At 16 months after stereotactic P-32 interstitial radiotherapy, the tumor (arrow) was clearly smaller (B). The tumor volume (arrow) progressively decreased as noted on an image obtained 39 months after radiotherapy (C). By 6 years after treatment (D), the cystic tumor (arrow) had completely disappeared, leaving some residual calcification.

clinical features of giant posterior fossa cystic craniopharyngiomas include increased intracranial pressure due to the large volume of the tumors and compromised cranial nerve functions caused by tumor extension along the cistern and subarachnoid regions. The optic nerve as well as the auditory nerve, facial nerve, abducens nerve, and oculomotor nerve are the most commonly involved nerves in cases of giant posterior fossa cystic craniopharyngiomas. However, identifying an effective treatment for these craniopharyngiomas remains an important challenge in neurosurgery. ${ }^{34}$ In this study, we reviewed the treatment effects of isotope interstitial radiotherapy in a relatively larger number of cases of giant posterior fossa cystic craniopharyngiomas. ${ }^{3,6,9,11,18,28,35}$

The treatment options for giant posterior fossa cystic craniopharyngiomas also remain controversial. Due to the benign pathological nature of these tumors, resection should be the ideal choice, and several groups have recently achieved good results. Giant posterior fossa cystic craniopharyngiomas often involve more important intracranial structures than common craniopharyngiomas in the sellar region. Moreover, despite the clear boundary between the cyst wall and the normal brain tissue, removing the tumor requires pulling the cyst wall from the surrounding tissue. Thus, cyst removal will inevitably cause injury to neurovascular structures. Therefore, total tumor resection
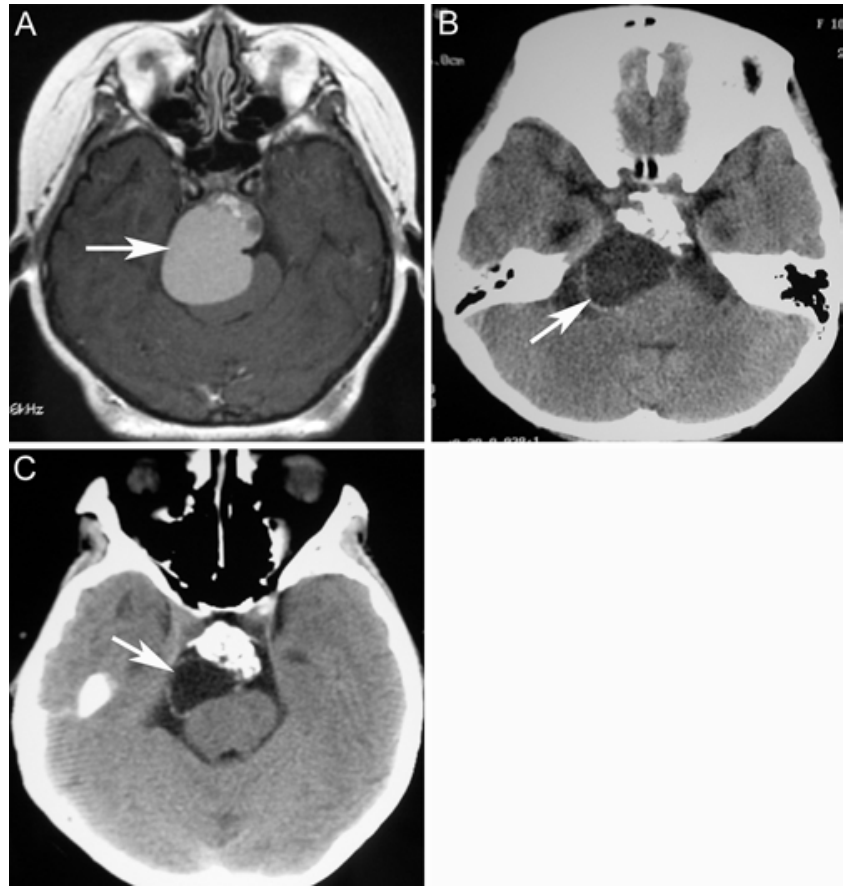

FIG. 2. Case 5. Axial T1-weighted MR images in a 9-year-old boy diagnosed with craniopharyngioma by MRI due to headache for 3 months with nausea/vomiting for 3 days. We observed a giant craniopharyngioma (arrow) originating from the saddle area and extending to the posterior fossa (A). At 14 months after stereotactic P-32 interstitial radiotherapy, the tumor (arrow) had shrunk to $50 \%$ of its initial volume (B). Two years after treatment, the tumor volume (arrow) progressively decreased to $75 \%$ of its initial volume (C).

is accompanied by a high risk for morbidity and mortality. ${ }^{21,30,34}$ Moreover, radical tumor resection cannot rule out the possibility of local tumor recurrence, even if postoperative MRI shows that no residual tumor remains. ${ }^{4,5,7}$ Additionally, some long-term survivors after complete resection experience a poor quality of life. ${ }^{8,12,17,19,20}$ Thus, partial resection associated with or without postoperative treatment has been proposed, including regular radiotherapy or interstitial radiotherapy, especially for tumors with hypothalamus involvement confirmed by preoperative imaging. ${ }^{5,7,8}$ Complete 1 -stage resection of suprasellar and posterior fossa tumors through the Kawase approach has been reported as an effective surgical treatment, ${ }^{11,18}$ although other studies have proposed multistage operations involving a craniotomy and resection of suprasellar tumors through the petrous and bilateral frontal region in the first stage.$^{6}$ Then a craniotomy is performed via the suboccipital approach to resect the tumor in the posterior fossa before formation of postoperative adhesion in the second stage. Gangemi et al. reported that endoscopic cyst drainage could be performed to reduce the size of the tumor, and then a craniotomy resection could be subsequently used. ${ }^{9}$ These authors stressed that endoscopic drainage can rapidly reduce intracranial pressure, improve the circulation of CSF, and alleviate adhesion between the tumor and surrounding vital structures, which facilitates subsequent complete resection.

In recent years, 22 cases of giant posterior fossa cystic 

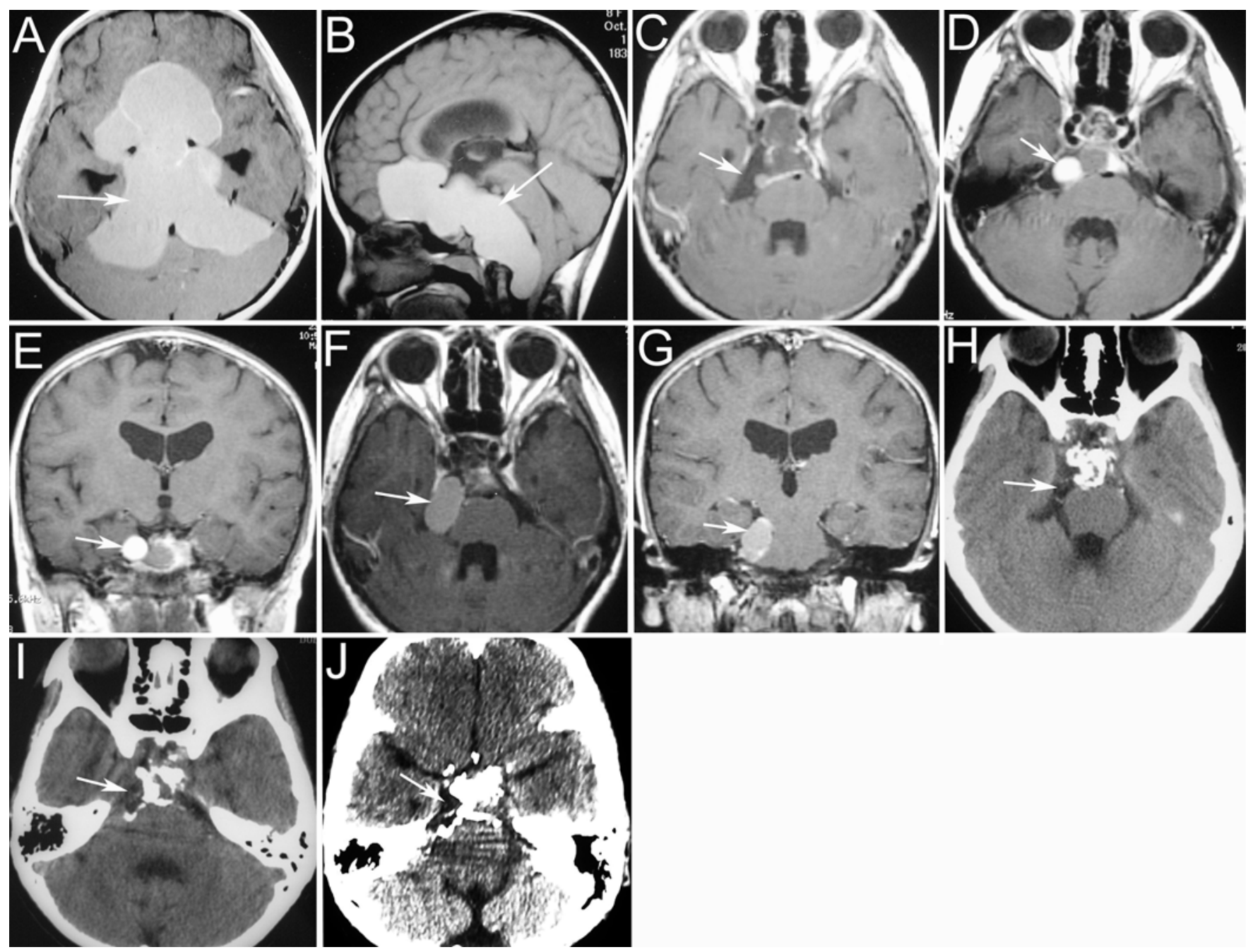

FIG. 3. Case 1. Axial (A, C, D, F), sagittal (B), and coronal (E and G) T1-weighted MR images and axial CT scans (H-J) in an 8-year-old girl diagnosed by MRI with a giant craniopharyngioma after experiencing intermittent headache and vomiting associated with binaural hearing loss for 4 months. The tumor (arrows) extended backward to the posterior cranial fossa and reached the cervical canal (A and B). Stereotactic P-32 tumor interstitial radiotherapy was performed, and the tumor disappeared (arrow) after 1 year (C). At 1.5 years after treatment, new cystic tumors (arrows) emerged in the right parasellar area (D and E). These new tumors disappeared 1.5 years after the second dose of radiotherapy, but a new cystic tumor (arrows) appeared in the cerebellopontine angle (F and G). A third course of interstitial radiotherapy was therefore applied. CT scans at 5, 6, and 9 years after the initial treatment demonstrated that the tumors had disappeared (arrows), with calcifications remaining in the sellar region (H-J).

craniopharyngiomas treated with surgery have been reported. A total of 35 surgeries were performed with an average of 1.59 operations per case. Complete resection was achieved in 16 cases, subtotal resection in 2 cases, and partial resection in 4 cases. Following surgical intervention, 2 patients died at 4 and 12 days postoperatively. One patient underwent 2 surgical interventions for complete resection of the tumor but died 3 years later. Only 13 cases were followed up for more than 3 months. Although no tumor progression was found in these cases, 3 patients required hormone replacement therapy. Therefore, the treatment outcome was not satisfactory.

A large number of studies have confirmed that P-32 interstitial radiation therapy can treat cystic craniopharyngiomas with satisfactory short-term and long-term results. ${ }^{2,13-15,26}$ However, the best indication for this treatment was for patients with a simple cyst and a tumor volume of 3-40 $\mathrm{ml}^{33}$ The therapeutic dose in these studies ranged from 50 to $1000 \mathrm{~Gy}$, with most patients receiving 200-300 Gy. $2,13-15,26,33$ The treatment outcome was not satisfactory and there was a high recurrence rate if the dose was less than $200 \mathrm{~Gy}$. We did not find any reports for the treatment of giant craniopharyngiomas using isotope radiotherapy. In this study, although the tumor volume was much larger, with a range from 65 to $215 \mathrm{ml}$, we used a dose of $150 \mathrm{~Gy}$ for treatment after determining that the tumor size would decrease after drainage. During the follow-up period, no apparent related complications were detected. Among the 27 cysts treated in 20 patients, 14 disappeared and 13 significantly shrank. These results indicate that giant craniopharyngiomas in children are highly sensitive to interstitial radiotherapy. 
The most obvious clinical outcome after surgery was alleviated intracranial hypertension, and this mitigation was sustained unless the tumor was recurrent. After cystic fluid drainage, the cranial nerve compression symptoms were also fully alleviated. The degree of cranial nerve damage recovery depended on the reversibility of the nerve function. Fortunately, the cranial nerve compression had formed slowly, and the nerve therefore developed tolerance to compression. When this compression was lifted, the nerve functions could be partially or completely restored. In this study, 13 cranial nerves other than the optic nerve were involved. After treatment, 11 cranial nerves were completely restored and 1 was partially restored. This result suggests that a good outcome is possible for affected cranial nerves after treatment. We also found that the endocrine disorder symptoms were mild in all 20 patients and were most likely due to the giant cystic craniopharyngiomas extending into low-pressure areas with relatively less compression on the optic nerve, thalamus, and pituitary.

\section{Conclusions}

This study showed that isotope interstitial radiotherapy following drainage is an effective method for the treatment of giant posterior fossa cystic craniopharyngiomas, which can quickly relieve intracranial hypertension, achieve a high rate of tumor control, and result in recovery of the damaged cranial nerve, accompanied by a low complication rate and good quality of life.

\section{References}

1. Al-Mefty O, Hassounah M, Weaver P, Sakati N, Jinkins JR, Fox JL: Microsurgery for giant craniopharyngiomas in children. Neurosurgery 17:585-595, 1985

2. Barriger RB, Chang A, Lo SS, Timmerman RD, DesRosiers C, Boaz JC, et al: Phosphorus-32 therapy for cystic craniopharyngiomas. Radiother Oncol 98:207-212, 2011

3. Buhl R, Lang EW, Barth H, Mehdorn HM: Giant cystic craniopharyngiomas with extension into the posterior fossa. Childs Nerv Syst 16:138-142, 2000

4. Caldarelli M, di Rocco C, Papacci F, Colosimo C Jr: Management of recurrent craniopharyngioma. Acta Neurochir (Wien) 140:447-454, 1998

5. Carmel PW, Antunes JL, Chang CH: Craniopharyngiomas in children. Neurosurgery 11:382-389, 1982

6. Connolly ES Jr, Winfree CJ, Carmel PW: Giant posterior fossa cystic craniopharyngiomas presenting with hearing loss. Report of three cases and review of the literature. Surg Neurol 47:291-299, 1997

7. Fahlbusch R, Honegger J, Paulus W, Huk W, Buchfelder M: Surgical treatment of craniopharyngiomas: experience with 168 patients. J Neurosurg 90:237-250, 1999

8. Fischer EG, Welch K, Shillito J Jr, Winston KR, Tarbell NJ: Craniopharyngiomas in children. Long-term effects of conservative surgical procedures combined with radiation therapy. J Neurosurg 73:534-540, 1990

9. Gangemi M, Seneca V, Mariniello G, Colella G, Magro F: Combined endoscopic and microsurgical removal of a giant cystic craniopharyngioma in a six-year-old boy. Clin Neurol Neurosurg 111:472-476, 2009

10. Garnett MR, Puget S, Grill J, Sainte-Rose C: Craniopharyngioma. Orphanet J Rare Dis 2:18, 2007

11. Goyal A, Singh AK, Sinha S: Giant cystic craniopharyn- gioma with posterior fossa extension. Pediatr Neurosurg 37:50-51, 2002

12. Guidetti B, Fraioli B: Craniopharyngiomas. Results of surgical treatment. Acta Neurochir Suppl (Wien) 28:349-351, 1979

13. Hasegawa T, Kondziolka D, Hadjipanayis CG, Lunsford LD: Management of cystic craniopharyngiomas with phosphorus-32 intracavitary irradiation. Neurosurgery 54:813-822, 2004

14. Julow J, Backlund EO, Lányi F, Hajda M, Bálint K, Nyáry I, et al: Long-term results and late complications after intracavitary yttrium-90 colloid irradiation of recurrent cystic craniopharyngiomas. Neurosurgery 61:288-296, 2007

15. Julow J, Lányi F, Hajda M, Szeifert GT, Viola A, Bálint K, et al: Stereotactic intracavitary irradiation of cystic craniopharyngiomas with yttrium-90 isotope. Prog Neurol Surg 20:289-296, 2007

16. Karavitaki N, Cudlip S, Adams CB, Wass JA: Craniopharyngiomas. Endocr Rev 27:371-397, 2006

17. Katz EL: Late results of radical excision of craniopharyngiomas in children. J Neurosurg 42:86-93, 1975

18. Kiran NA, Suri A, Kasliwal MK, Garg A, Ahmad FU, Mahapatra AK: Gross total excision of pediatric giant cystic craniopharyngioma with huge retroclival extension to the level of foramen magnum by anterior trans petrous approach: report of two cases and review of literature. Childs Nerv Syst 24:385-391, 2008

19. Landolt AM, Zachmann M: Results of transsphenoidal extirpation of craniopharyngiomas and Rathke's cysts. Neurosurgery 28:410-415, 1991

20. Lunsford LD, Pollock BE, Kondziolka DS, Levine G, Flickinger JC: Stereotactic options in the management of craniopharyngioma. Pediatr Neurosurg 21 (Suppl 1):90-97, 1994

21. Maira G, Anile C, Albanese A, Cabezas D, Pardi F, Vignati A: The role of transsphenoidal surgery in the treatment of craniopharyngiomas. J Neurosurg 100:445-451, 2004

22. Maira G, Anile C, Rossi GF, Colosimo C: Surgical treatment of craniopharyngiomas: an evaluation of the transsphenoidal and pterional approaches. Neurosurgery 36:715-724, 1995

23. Minamida Y, Mikami T, Hashi K, Houkin K: Surgical management of the recurrence and regrowth of craniopharyngiomas. J Neurosurg 103:224-232, 2005

24. Patterson RHJ Jr, Danylevich A: Surgical removal of craniopharyngiomas by the transcranial approach through the lamina terminalis and sphenoid sinus. Neurosurgery 7:111-117, 1980

25. Petito CK, DeGirolami U, Earle KM: Craniopharyngiomas: a clinical and pathological review. Cancer 37:1944-1952, 1976

26. Pollock BE, Lunsford LD, Kondziolka D, Levine G, Flickinger JC: Phosphorus-32 intracavitary irradiation of cystic craniopharyngiomas: current technique and long-term results. Int J Radiat Oncol Biol Phys 33:437-446, 1995

27. Schefter JK, Allen G, Cmelak AJ, Johnson M, Toms S, Duggan $\mathrm{D}$, et al: The utility of external beam radiation and intracystic $32 \mathrm{P}$ radiation in the treatment of craniopharyngiomas. J Neurooncol 56:69-78, 2002

28. Sener RN, Kismali E, Akyar S, Selcuki M, Yalman O: Large craniopharyngioma extending to the posterior cranial fossa. Magn Reson Imaging 15:1111-1112, 1997

29. Shirane R, Ching-Chan S, Kusaka Y, Jokura H, Yoshimoto T: Surgical outcomes in 31 patients with craniopharyngiomas extending outside the suprasellar cistern: an evaluation of the frontobasal interhemispheric approach. J Neurosurg 96:704-712, 2002

30. Symon L, Pell MF, Habib AH: Radical excision of craniopharyngioma by the temporal route: a review of 50 patients. Br J Neurosurg 5:539-549, 1991

31. Tomita T, Bowman RM: Craniopharyngiomas in children: 
surgical experience at Children's Memorial Hospital. Childs Nerv Syst 21:729-746, 2005

32. Van Effenterre R, Boch AL: Craniopharyngioma in adults and children: a study of 122 surgical cases. J Neurosurg 97:3-11, 2002

33. Voges J, Sturm V, Lehrke R, Treuer H, Gauss C, Berthold F: Cystic craniopharyngioma: long-term results after intracavitary irradiation with stereotactically applied colloidal betaemitting radioactive sources. Neurosurgery 40:263-270, 1997

34. Yaşargil MG, Curcic M, Kis M, Siegenthaler G, Teddy PJ, Roth P: Total removal of craniopharyngiomas. Approaches and long-term results in 144 patients. J Neurosurg 73:3-11, 1990

35. Young SC, Zimmerman RA, Nowell MA, Bilaniuk LT, Hackney DB, Grossman RI, et al: Giant cystic craniopharyngiomas. Neuroradiology 29:468-473, 1987
36. Zuccaro G: Radical resection of craniopharyngioma. Childs Nerv Syst 21:679-690, 2005

\section{Author Contributions}

Conception and design: S Liu, Yu, Zhang. Acquisition of data: Yu, R Liu, Y Wang, H Wang, P Wang, Chen. Analysis and interpretation of data: all authors. Drafting the article: S Liu, Yu. Critically revising the article: all authors. Reviewed submitted version of manuscript: all authors. Approved the final version of the manuscript on behalf of all authors: S Liu. Administrative/ technical/material support: Yu, Zhang, R Liu, Y Wang, H Wang, P Wang, Chen. Study supervision: S Liu, Yu.

\section{Correspondence}

Song Liu, U 1195, INSERM-Université Paris-Sud, 80 rue du General Leclerc, Le Kremlin-Bicêtre 94276, France. email: song. liu@inserm.fr. 